\title{
Gastrobronchial Fistula After Caustic Injury Due to Lye Ingestion
}

Gastrobronchial fistula is an extremely rare occurrence. Most cases result from postoperative complications of esophagogastric surgery [1] and rarely from traumatic injury [2], subphrenic abscess [3], perforating peptic ulcer [4], or malignancies [5]. We observed the delayed development of a gastrobronchial fistula after massive caustic injury of the stomach due to suicidal lye ingestion.

A 32-year-old woman was admitted after suicidal ingestion of about $100 \mathrm{ml}$ of a $25 \%$ ammonia solution. Plain films of the chest and abdomen revealed no perforation. From the 5th day chest roentgenograms consistently documented a leftsided opacification that was sonographically echogenic and was located subphrenically. Endoscopic surveillance revealed deep ulcerations in the midbody and fundus which were covered by fibrinoid membranes which sloughed incrementaly. After 10 weeks the fundus appeared thin and translucent. Recurring high-grade fever occurred in the 11th

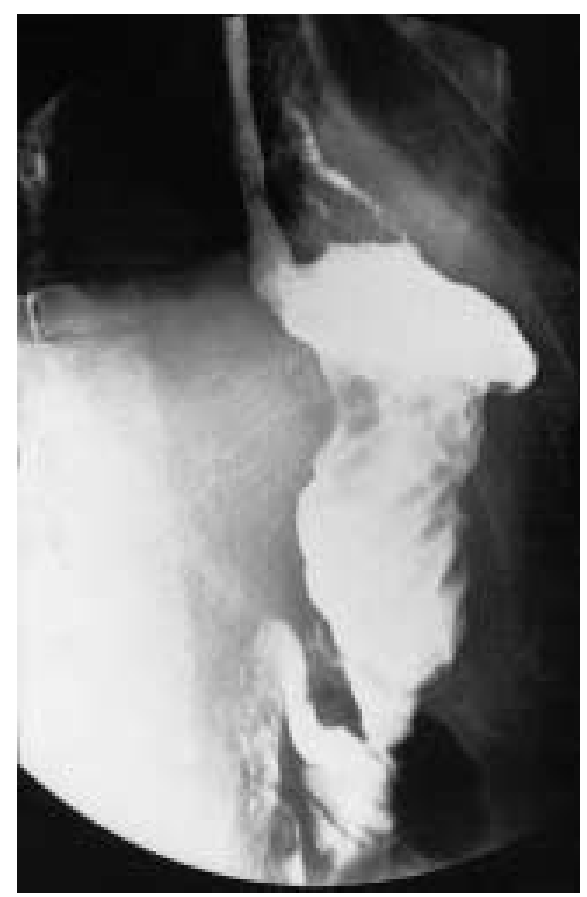
fundus.

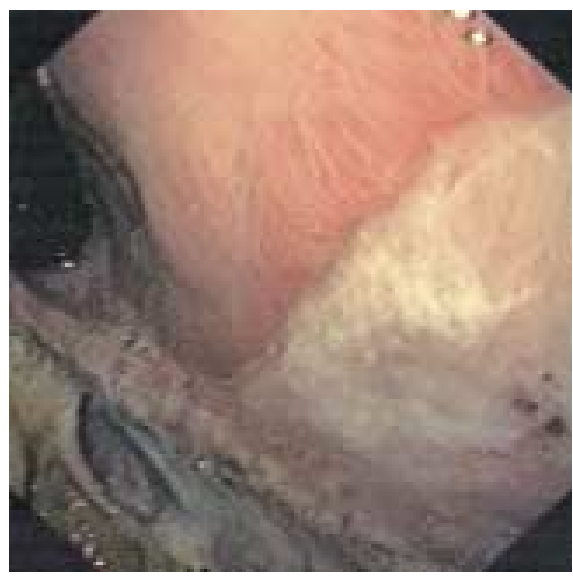

Figure 2 Endoscopic view of bronchial structures through a wide fistula in the gastric

trobronchial fistula due to subphrenic abscess can be treated conservatively without surgery over several weeks. vealed a passage from the fundus into the subphrenic cavity and into the bronchial system (Figure $\mathbf{1}$ ). At this time the patient rejected the proposed surgical procedure. With antibiotic coverage and parenteral nutrition the subphrenic abscess completely regressed, while the fistula enlarged. In the 16th week bronchial structures could be identified on gastroscopy (Figure 2). In the 20th week the fistula was closed by a subphrenic net seal and a partial resection of the fundus.

Complications of lye ingestion are typically esophageal and antral strictures as well as perforations. In this case, massive necrosis of the fundus resulted in a subphrenic inflammation. Secondarily, with a delay of 10 weeks, this inflammation caused perforation of the fundus and the diaphragm [3]. Because of the patient's refusal to undergo prompt surgical therapy, this case also demonstrates that gas-

\section{E. A. Purucker, S. Südfeld, S. Matern}

Department of Internal Medicine III, Medical Faculty, Technical University, Aachen, Germany

\section{References}

1 Stal JM, Hanly PJ, Darling GE. Gastrobronchial fistula: an unusual complication of esophagectomy. Ann Thorac Surg 1994; 58: 886-887

${ }^{2}$ Al-Qudah A. Traumatic gastrobronchial fistula: case report and review of the literature. J Pediatr Surg 1997; 32: 1798 1800

${ }^{3}$ Angelillo VA, O’Donohue Jr WJ, Campbell JC et al. Gastrobronchial fistula secondary to a subphrenic abscess. Chest 1983; 84: 85-86

${ }^{4}$ Matsuoka T, Nagai Y, Muguruma K et al. Liver penetration and gastrobronchial fistula: unusual complications of a peptic ulcer. Am Surg 1995; 61: 492 - 494

${ }^{5}$ Cameron EW, Colby JM, Swanson RS. Gastrobronchial fistula in untreated lymphoma. J Thorac Imaging 1996; 11: $150-152$

\section{Corresponding Author}

\section{E. A. Purucker}

Department of Internal Medicine III

Medical Faculty

Technical University

Pauwelsstrasse 30

52057 Aachen

Germany

Fax: $\quad+49-241-8082455$

E-mail: epurucker@ukaachen.de
Figure 1 Upper gastrointestinal contrast study demonstrating a subphrenic cavity and bronchial structures. 